\title{
Photophysiology of a mesophotic coral 3 years after transplantation to a shallow environment
}

\author{
Or Ben-Zvi, Raz Tamir, Nir Keren, Dan Tchernov, Ilana Berman-Frank, Yuval Kolodny, Tal \\ Benaltabet, Harel Bavli, Mor Friedman, Noga Glanz-Idan, Hadar Traugott, Yossi Loya \& Gal Eyal
}

Abstract

With shallow coral reefs suffering from an ongoing rapid decline in many regions of the world, the interest in studies on mesophotic coral ecosystems $(30-150 \mathrm{~m})$ is growing rapidly. While most photoacclimation responses in corals were documented within the upper $30 \mathrm{~m}$ of reefs, in the present study we transplanted fragments of a strictly mesophotic species from the Red Sea, Euphyllia paradivisa, from $50 \mathrm{~m}$ to $5 \mathrm{~m}$ for a period of 3 years. Following the retrieval of the corals, their physiological and photosynthetic properties of the corals were tested. The transplanted corals presented evidence of photosynthetic acclimation to the shallow habitat, lower sensitivity to photoinhibition, and a high survival percentage, while also demonstrating a reduced ability to utilize low light compared to their mesophotic counterparts. This long-term successful transplantation from a mesophotic depth to a shallow habitat has provided us with insights regarding the ability of mesophotic corals and their symbionts to survive and withstand shallow environments, dominated by a completely different light regime. The extensive characterization of the photobiology of E. paradivisa, and its photoacclimation response to a high-light environment also demonstrates the plasticity of corals and point out to mechanisms different than those reported previously in shallower corals.

Introduction

Scleractinian corals, the building blocks of coral reefs, are characterized by their symbiosis with endocellular dinoflagellates, mostly from the family Symbiodiniaceae, commonly referred to as zooxanthellae (Trench and Harley 1971; Muscatine and Porter 1977; LaJeunesse et al. 2018). Mesophotic coral ecosystems (MCEs) are light-dependent coral reefs habitats found at depths between $30 \mathrm{~m}$ and approximately $150 \mathrm{~m}$. MCEs are characterized by a strong solar irradiance gradient, resulting in light fluxes that vary between 5 and $100 \mu$ mol photons $\mathrm{m}^{-2} \mathrm{~s}^{-1}$ (Hinderstein et al. 2010; Einbinder et al. 2016; Eyal et al. 2016). Consequently, mesophotic corals might experience more than 100 -fold lower irradiance levels than those experienced by shallow corals. MCEs are also characterized by narrower light spectrum, primarily blue light spectrum centered around $467 \mathrm{~nm}$, rather than the wider spectral range of shallow waters (Lesser et al. 2009; reviewed by Kahng et al. 2019). Although corals respond to a variety of environmental factors, such as temperature (Fitt et al. 2009; Cantin et al. 2010) and water motion (Jokiel 1978a), light quality and irradiance levels have been suggested to play a key role in coral ecology (Veron 1995). Light affects coral settlement (Maida et al. 1994; Mundy and Babcock 1998), movement (Yamashiro and Nishira 1995), and competition with other organisms (Benayahu and Loya 1985). Primarily, light is an essential requirement because it enhances the calcification and enables photosynthesis of the coral and its algal symbionts (Chalker et al. 1983; Falkowski et al. 1990; Lesser 2000; Beer et al. 2014; Cohen et al. 2016). Photoacclimation refers to acclimation to a particular light environment (Falkowski and Dubinsky 1981). Corals may shift from autotrophic nutrition to heterotrophic or mixotrophic feeding in deeper habitats; 
therefore, low-light environments (Mass et al. 2007; Alamaru et al. 2009; Lesser et al. 2009) display depth-related changes in morphology to enable maximal light capture (Muscatine 1990; Anthony et al. 2005; Nir et al. 2011) or prevent self-shading (Enríquez et al. 2017) and reorganize their photosystems (Lesser 2000). As the severe deterioration of shallow coral reefs continues globally (Hughes et al. 2018), the interest and investigative studies on MCEs are growing rapidly (Loya et al. 2016), including the reproduction patterns of coral species (Holstein et al. 2015; EyalShaham et al. 2016; Feldman et al. 2018; Shlesinger et al. 2018), community composition (Kahng et al. 2010, Kramer et al. 2019; Tamir et al. 2019), and the mechanisms of acclimation to this unique environment (Nir et al. 2011; Eyal et al. 2016; Groves et al. 2018; Eyal et al. 2019). The "Deep Reef Refugia Hypothesis," coined by Bongaerts et al. (2010), discusses the potential role of mesophotic reefs to provide a source of propagules that may replenish the shallow reefs in cases of extreme loss. The dominance of the coral Euphyllia paradivisa in the mesophotic reefs of the Gulf of Eilat/Aqaba (GoE/A), and its complete absence from the shallow reef, suggest its robust adaptation to deep habitats (Eyal et al. 2016). In this study, we thus examined the physiological and photosynthetic characteristics of E. paradivisa and its potential photoacclimation to different depths and light environments 3 years after transplantation from $50 \mathrm{~m}$ to $5 \mathrm{~m}$ depth.

Materials and methods

\section{Experimental design and coral collection}

Six colonies of the scleractinian coral Euphyllia paradivisa Veron (1990) were collected at $50 \mathrm{~m}$ depth in front of the Dekel Beach, Eilat ( $\left.29^{\circ} 32^{\prime} 17^{\prime \prime} \mathrm{N}, 34^{\circ} 56^{\prime} 56^{\prime \prime} \mathrm{E}\right)$. The colonies were tagged and fragmented, with 4-8 polyps from each colony left at their native environment of $50 \mathrm{~m}$ depth (i.e., the "deep" fragments). The remaining 4-6 polyps from each colony were transplanted to a coral nursery at $5 \mathrm{~m}$ depth (i.e., the "shallow" fragments) in front of the Interuniversity Institute for Marine Science (IUI), Eilat ( $29^{\circ} 30^{\prime} 16^{\prime \prime} \mathrm{N}, 34^{\circ} 55^{\prime} 7^{\prime \prime}$ E). All fragments were left at the sites for 3 years to allow the corals to fully acclimate throughout seasonal and yearly variation and were simultaneously retrieved for analysis at the end of this period. Following the coral retrieval and prior to analysis $(24 \mathrm{~h})$, the deep fragments were kept under a lighting filter "Lagoon blue" (Lee Filters, Hampshire, UK) that creates a light environment similar to that found at 40-50 m; and the shallow fragments were kept under ambient sunlight in running seawater aquaria systems.

\section{Zooxanthellae density and chlorophyll a concentration}

Tentacles from each fragment were sampled and weighed for normalization. The tissue was mechanically broken, centrifuged and separated into host and symbiont fractions. Zooxanthellae density $\left(10^{5}\right.$ cells $\mathrm{mg}$ host tissue $\left.{ }^{-1}\right)$ was determined with a hemocytometer under a light microscope. Following the isolation of the algal fraction from the host tissue, chlorophyll was extracted with $100 \%$ cold acetone for $15 \mathrm{~h}$ and cellular chlorophyll a concentrations (pg chlorophyll a cell ${ }^{-1}$ ) were calculated following Jeffrey and Humphrey (1975).

\section{Chlorophyll fluorescence measurements}


Following retrieval, all fragments were immediately dark-incubated for $1 \mathrm{~h}$ and photosystem II (PSII) maximal quantum yield $\left(F_{v} / F_{m}\right)$ was measured for each coral fragment, using a Diving-Pulse Amplitude Modulation fluorometer (Diving-PAM; Walz $\mathrm{GmbH}$, Effeltrich, Germany) with white saturating pulse (4000 $\mu \mathrm{mol}$ photons $\mathrm{m}^{-2}$, white light, $500 \mathrm{~ms}$ ).

Fluorescence Induction and Relaxation (FIRe) fluorometer (Satlantic, Nova Scotia, Canada) was used to measure $F_{v} / F_{m}$, effective quantum yield $\left(\Delta F / F_{m}{ }^{\prime}\right)$, rate of PSIl acceptor side reduction $\left(\tau_{\mathrm{Qa}}\right), \mathrm{PSII}$ absorption cross section $\left(\sigma_{\mathrm{PSII}}\right)$, and non-photochemical quenching (NPQ) values. Each fragment was measured using the FIRe blue light saturation pulse $\left(10,000 \mu \mathrm{mol}\right.$ photons $\mathrm{m}^{-2}$, $80 \mu \mathrm{s})$ after $1 \mathrm{~h}$ incubation at increasing light intensities $(0,30,150$, and $290 \mu \mathrm{mol}$ photons $\left.\mathrm{m}^{-2} \mathrm{~s}^{-1}\right)$.

Imaging-PAM (Maxi-version, Walz GmbH, Effeltrich, Germany) was used to measure and calculate $F_{v} / F_{m}, \Delta F / F_{m}{ }^{\prime}, N P Q$, and the approximate relative electron transport rate (rETR). Each fragment was measured with an actinic light saturation pulse $\left(2700 \mu \mathrm{mol}\right.$ photons $\mathrm{m}^{-2} \mathrm{~s}^{-1}$, $800 \mathrm{~ms}$ ) after $15 \mathrm{~min}$ incubation at increasing light intensities $(0,21,56,111,186,281,396,531$, and $701 \mu \mathrm{mol}$ photons $\mathrm{m}^{-2} \mathrm{~s}^{-1}$ ).

\section{Respiration metabolic chambers}

Shallow and deep fragments ( $n=9$ from each depth) of similar size were incubated in 250-ml custom-made acrylic metabolic chambers containing $0.22 \mu$ filtered seawater at $23^{\circ} \mathrm{C}$ (ambient sea temperature). Prior to incubation, fragment volume was measured by buoyant weight for normalization (Jokiel 1978b). Fragments were incubated under increasing light intensities for 20 min at each intensity $\left(0,10,40,140,250,400,600 \mu \mathrm{mol}\right.$ photons $\left.\mathrm{m}^{-2} \mathrm{~s}^{-1}\right)$ using two fullspectrum metal halide lamp $(400 \mathrm{~W}, 5000 \mathrm{~K}, 50 \mathrm{~Hz}$, golden light, Israel). Light intensity $(E)$ was recorded using a LI-COR LI-250A light meter (LI-COR, NE, USA). Oxygen evolution was monitored using ProODO Optical Dissolved Oxygen meter (YSI Inc., OH, USA) placed at the top of each chamber. Photosynthetic rates $(P)$ were calculated according to the difference between the final and initial $\mathrm{O}_{2}$ measurements of each incubation. Photosynthetic efficiency (i.e., slope at the light-limited region, $\alpha)$, irradiance compensation point $\left(E_{\mathrm{c}}\right)$, saturation irradiance $\left(E_{\mathrm{k}}\right)$, and maximal photosynthesis $\left(P_{\max }\right)$ were calculated through a hyperbolic fit function (Chalker 1981).

\section{Genetic identification of algal symbionts}

DNA was extracted from the algal pellet isolated from each fragment using DNeasy blood and tissue kit (Qiagen, MD, USA) according to the manufacturer's protocol for tissue samples. A $\sim 1000$ bp fragment of Symbiodiniaceae COXI mtDNA was amplified using the primers COXI_FOR2 and COXI_REV1 following Pochon et al. (2012). Samples were bi-directionally sequenced using $A B I 3730 X L$ sequencers (MCLAB, CA, USA). Symbiodiniaceae genera were determined based on the COXI sequences available on GeneBank.

\section{Statistical analyses}

All statistical analyses were performed with R software (Team 2013). Data were tested with a linear mixed effects model (LMEM) using the package $\{$ Ime4\} (Bates et al. 2015) and (ImerTest) (Kuznetsova et al. 2017) considering "depth" (i.e., the origin depth of the fragment) and "light" (i.e., light intensity when light curves were performed) as fixed effects and "colony" as a random 
effect. Post hoc analyses were performed using \{emmeans\} package (Lenth 2018). Models' residuals were checked visually for normality and with Levene's test for homogeneity of variance.

Results

\section{Physiological responses}

Fragments from both depths were retrieved from only four of the six colonies. Deep fragments from the remaining two colonies did not survive; therefore, for those colonies we retrieved only shallow fragments. The mean \pm SD survival rate of the transplanted fragments (i.e., shallow fragments) was $76 \pm 0.29 \%$ ( $n=25)$, while that of the control group (i.e., deep fragments) was $32 \pm 0.37 \%(n=10)$. Zooxanthellae density measurements revealed both significantly higher algal density (Fig. 1a; LMEM, $F=9.603, p=0.0045$ ) and chlorophyll a concentration (Fig. 1b; LMEM, $F=18.527, p=0.0002$ ) in the deep fragments compared to the shallow fragments.

Fig. 1
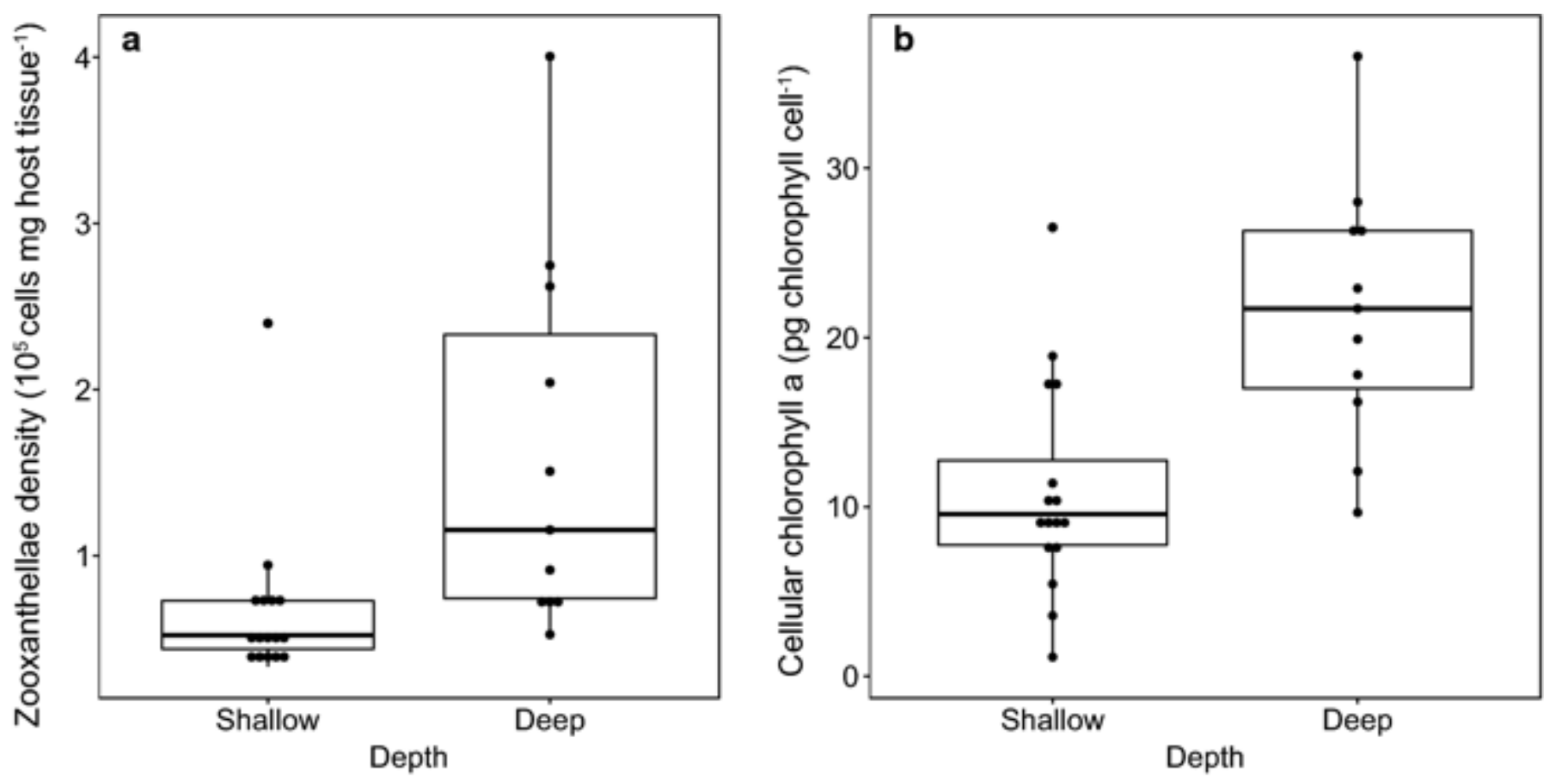

Zooxanthellae density and chlorophyll a concentration of Euphyllia paradivisa from depth of $50 \mathrm{~m}$ and following a deep-to-shallow transplantation. a Zooxanthellae density $\left(10^{5}\right.$ cells $\mathrm{mg}$ host tissue ${ }^{-1}$ ) and $\mathbf{b}$ cellular chlorophyll a concentration ( $\mathrm{pg}$ chlorophyll cell ${ }^{-1}$ ) in shallow $(5 \mathrm{~m}$; represented in gray, $n=16)$ and deep (50 m; represented in black, $n=11$ ) fragments of $E$. paradivisa. Boxes represent the upper and lower quartile, center lines represent medians, and whiskers extend to data measurements that are less than $1.5 *$ IQR away from first/third quartile

\section{Photosynthetic characteristics}

The maximal PSII quantum yield $\left(F_{v} / F_{m}\right)$ of the deep fragments measured by the Diving-PAM (Fig. 2) was found to be significantly higher (LMEM, $F=20.814, p=7.8 \mathrm{e}-5$ ) than that of the 
shallow fragments. This measurement was performed close to the retrieval time of the corals (and after the $1 \mathrm{~h}$ dark-incubation), and therefore best reflects the maximal potential quantum yield of the corals after the transplantation. Deep fragments had a mean $\pm \mathrm{SE} F_{v} / F_{m}$ value of $0.66 \pm 0.02$, while the mean shallow fragments value was $0.49 \pm 0.02$.

Fig. 2

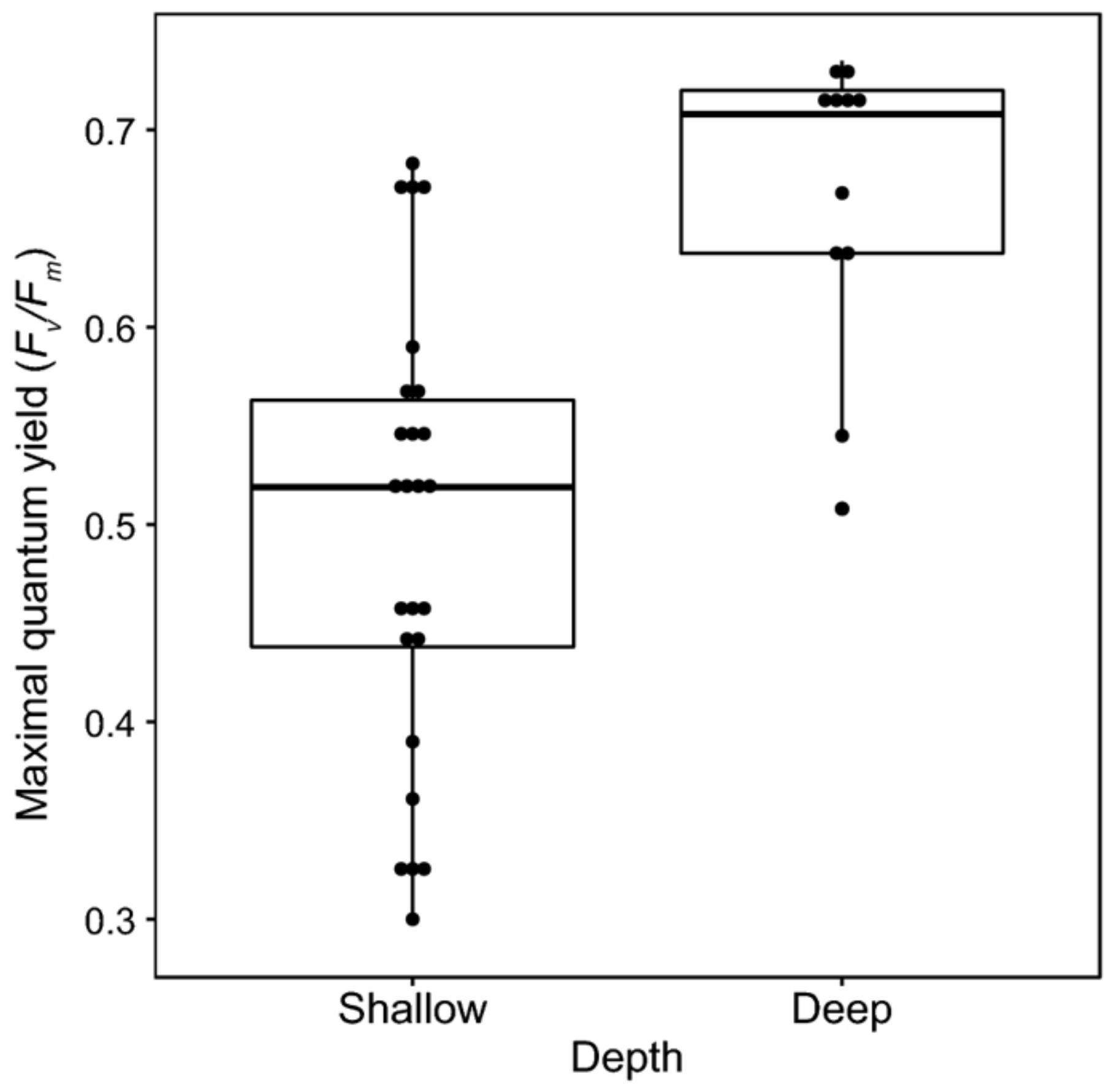

Maximal quantum yield $\left(F_{v} / F_{m}\right)$ of Euphyllia paradivisa from depth of $50 \mathrm{~m}$ and following a deepto-shallow transplantation. $F_{v} / F_{m}$ measurements obtained with a Diving-PAM of shallow ( $5 \mathrm{~m}$; represented in gray, $n=25)$ and deep $(50 \mathrm{~m}$; represented in black, $n=11)$ fragments of $E$. 
paradivisa following a $1 \mathrm{~h}$ dark-incubation. Boxes represent the upper and lower quartile, center lines represent medians, and whiskers extend to data measurements that are less than $1.5 * I Q R$ away from first/third quartile

Parameters obtained from the FIRe measurements (Fig. 3) also indicate that the deep fragments had significantly higher $F_{v} / F_{m}$ after the dark-incubation (Fig. 3a; pairwise comparison, $p=0.009$ ) and higher $\Delta F / F_{m}{ }^{\prime}(\mathrm{LMEM}, F=0.6816, p=0.066)$. This was accompanied by a lower $\sigma_{\text {PSII }}$ (Fig. $3 \mathrm{~b}$; LMEM, $F=0.414, p=0.743$ ), and lower $\tau_{\text {Qa }}$ values (Fig. $3 c$; LMEM, $F=4.13, p=0.051$ ). NPQ in the deep fragments was significantly lower (Fig. 3d, EMS 1 ; LMEM, $F=5.588, p=0.024$ ) than in the shallow fragments. The difference between the two depths (shallow vs. deep) was more notable under low-light incubation ( 0 and $30 \mu \mathrm{mol}$ photons $\mathrm{m}^{-2} \mathrm{~s}^{-1}$ ) compared to high light intensity (150 and $290 \mu \mathrm{mol}$ photons $\mathrm{m}^{-2} \mathrm{~s}^{-1}$ ) in all FIRe measurements.

Fig. 3
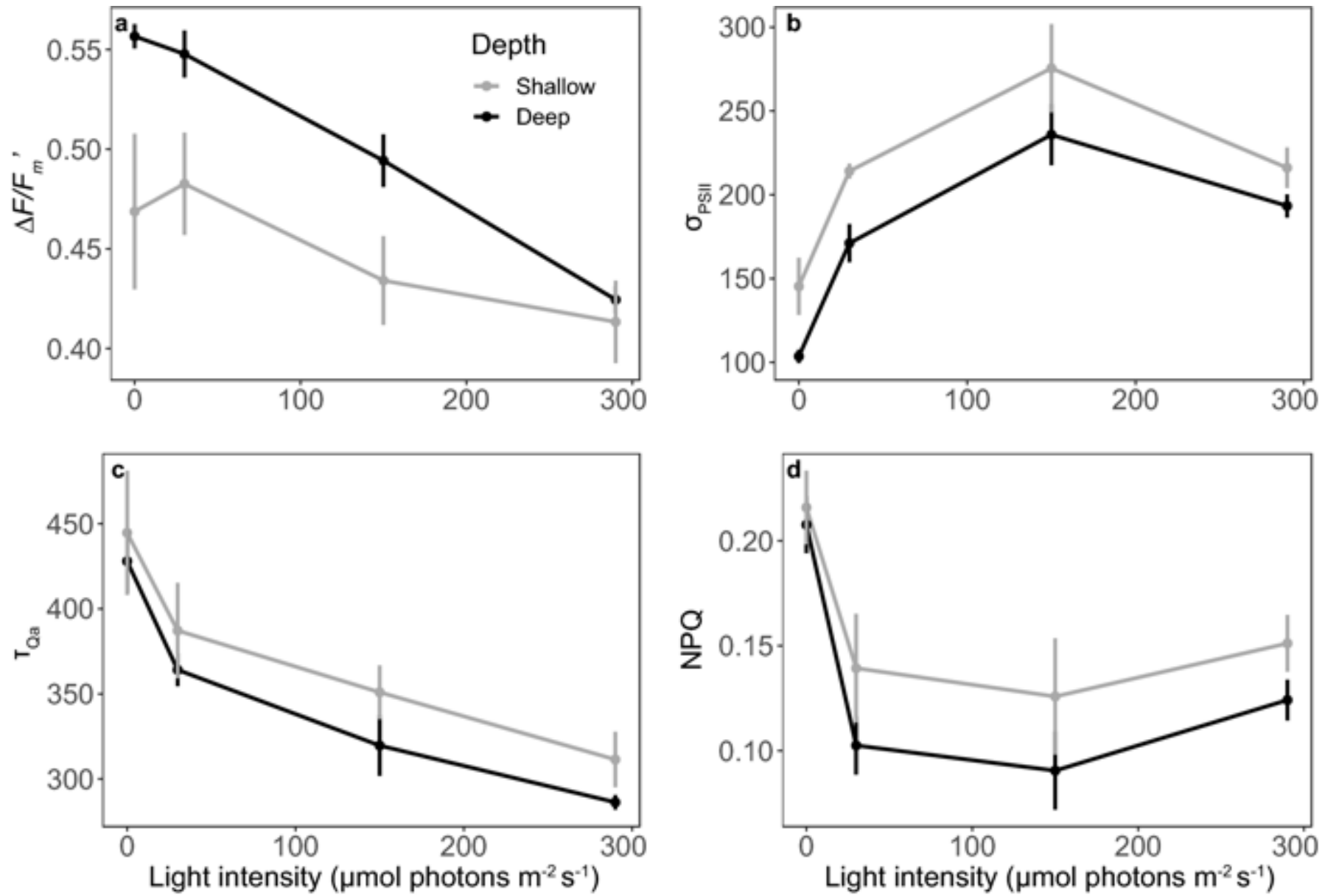

Photosynthetic parameters of Euphyllia paradivisa from depth of $50 \mathrm{~m}$ and following a deep-toshallow transplantation obtained using the FIRe system. Mean (dots) and SE (error bars) values of a effective quantum yield $\left(\Delta F / F_{m}{ }^{\prime}\right)$, b functional absorption cross section of PSII $\left(\sigma_{\text {PSII }}\right), \mathbf{c}$ time constant of electron transport on the acceptor side of PSII $\left(\tau_{\mathrm{Qa}_{\mathrm{a}}}\right)$, and $\mathbf{d}$ the residuals of nonphotochemical quenching (NPQ) of shallow ( $5 \mathrm{~m}$; represented in gray, $n=9)$ and deep (50 m; 
represented in black, $n=9$ ) fragments of E. paradivisa, following $1 \mathrm{~h}$ incubation under increasing actinic light intensities $\left(0,30,150\right.$, and $290 \mu \mathrm{mol}$ photons $\left.\mathrm{m}^{-2} \mathrm{~s}^{-1}\right)$

A comparison of the effective quantum yield in deep and shallow fragments from the same colony using the Imaging-PAM (Fig. 4a, c) revealed that under low-light conditions (up to $281 \mu \mathrm{mol}$ photons $\mathrm{m}^{-2} \mathrm{~s}^{-1}$ ) the shallow fragments demonstrated lower $\Delta F / F_{m}{ }^{\prime}$ while under light intensities higher than $281 \mu \mathrm{mol}$ photons $\mathrm{m}^{-2} \mathrm{~s}^{-1}$, they became more efficient in utilizing the photons for photosynthesis. The Imaging-PAM also allowed us to notice that the skeleton area is photosynthetically active as well. However, photosynthesis performed by photosynthetically active organisms, on or inside the skeleton, was less efficient than the photosynthesis performed by the algal symbionts within the coral tissue.

Fig. 4
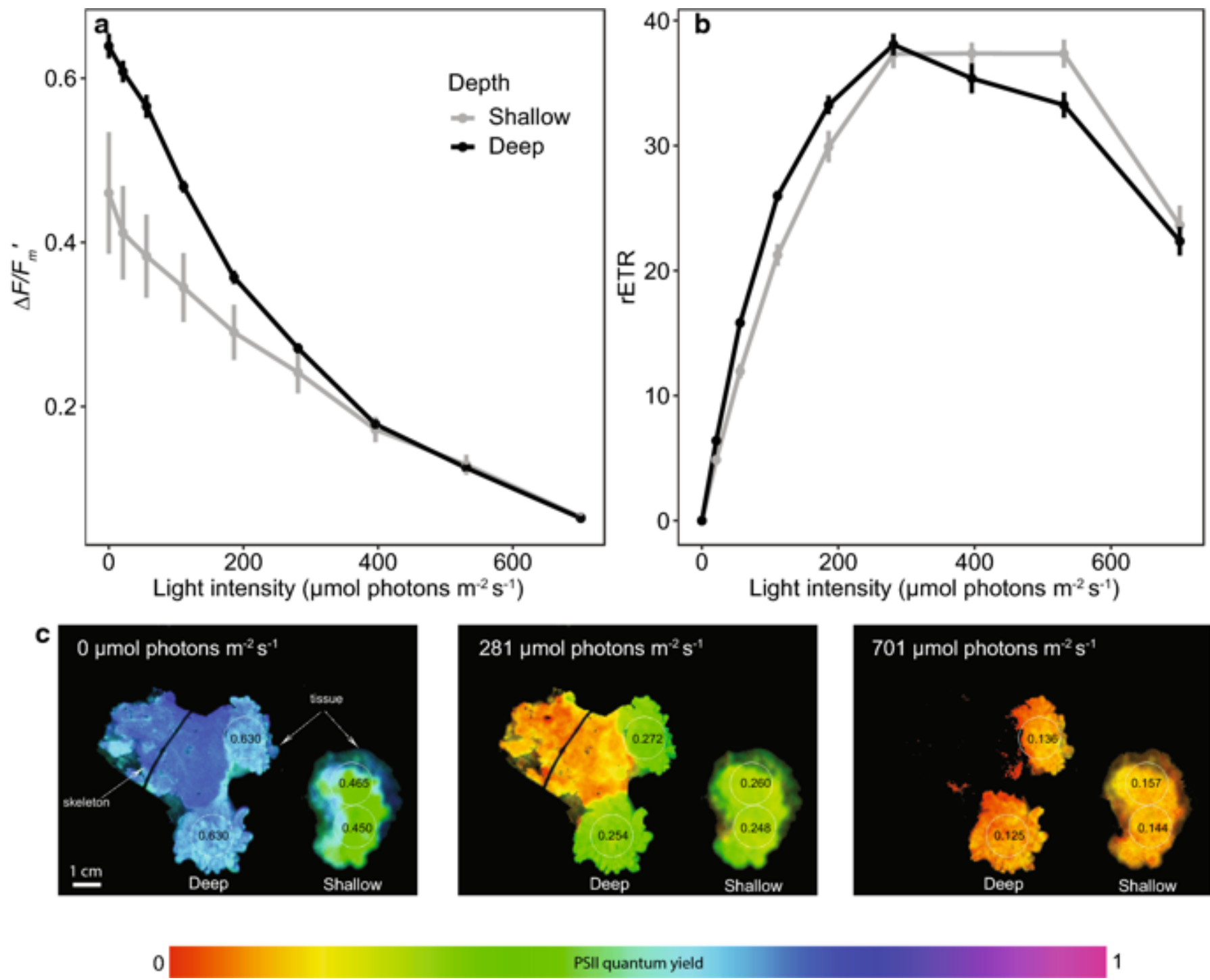

Photosynthetic parameters of Euphyllia paradivisa from depth of $50 \mathrm{~m}$ and following a deep-toshallow transplantation obtained from Imaging-PAM measurements. Mean (dots) and SE (error bars) values of a the effective quantum yield $\left(\Delta F / F_{m}{ }^{\prime}\right)$ and $\mathbf{b}$ relative electron transfer rate (rETR) 
of the shallow ( $5 \mathrm{~m}$; represented in gray, $n=3$ ) and deep ( $50 \mathrm{~m}$; represented in black, $n=3$ ) fragments of $E$. paradivisa, following $15 \mathrm{~min}$ incubation under increasing actinic light intensities $\left(0,21,56,111,186,281,396,531\right.$, and $701 \mu$ mol photons $\left.\mathrm{m}^{-2} \mathrm{~s}^{-1}\right)$. c Pseudo-colored images of the quantum yield of shallow polyps (fragment on the right) and deep polyps (fragment on the left) of the same colony measured after incubations under increasing light intensities of 0,281 , and $701 \mu \mathrm{mol}$ photons $\mathrm{m}^{-2} \mathrm{~s}^{-1}$. Circles represent the areas of interest (AOI) measured in each fragment

Accordingly, calculation of the relative electron transfer rates (rETR) from the light curves performed with the Imaging-PAM (Fig. 4b) shows that the shallow fragments had lower rETR (LMEM, $F=0.31, p=0.57$ ) compared to the deep fragments following low-light incubations (0$280 \mu \mathrm{mol}$ photons $\mathrm{m}^{-2} \mathrm{~s}^{-1}$ ). Under 300-400 $\mu \mathrm{mol}$ photons $\mathrm{m}^{-2} \mathrm{~s}^{-1}$ the rETR was equal, and under higher light $\left(>400 \mu \mathrm{mol}\right.$ photons $\left.\mathrm{m}^{-2} \mathrm{~s}^{-1}\right)$ the shallow fragments demonstrated higher $\mathrm{rETR}$ than the deep fragments.

\section{Photosynthesis versus Irradiance/energy (P-E) Curves}

Gross photosynthesis (Fig. 5a) was not significantly different between depths under $140 \mu \mathrm{mol}$ photons $\mathrm{m}^{-2} \mathrm{~s}^{-1}$, but was higher in the shallow fragments beyond this light intensity (LMEM, $F=2.749, p=0.02$ ). Comparing net photosynthesis (Fig. $5 b$ ) with the gross photosynthesis (Fig. 5a) demonstrates that shallow fragments had higher respiration rates than the deep fragments but also produced more oxygen. Parameters derived from P-E curves are summarized in Table 1. Shallow fragments reached the compensation point $\left(E_{c}\right)$ and saturation $\left(\mathrm{E}_{\mathrm{k}}\right)$ at higher light intensities ( $\mathrm{LMEM}, F=1.552, p=0.233$ and $F=1.092, p=0.293$, respectively) and displayed higher $\mathrm{P}_{\max }($ LMEM, $F=1.093, p=0.289)$, but

lower $\alpha$ (LMEM, $F=0.0349, p=0.853$ ) when normalized to the whole polyp volume (tissue and skeleton).

Fig. 5
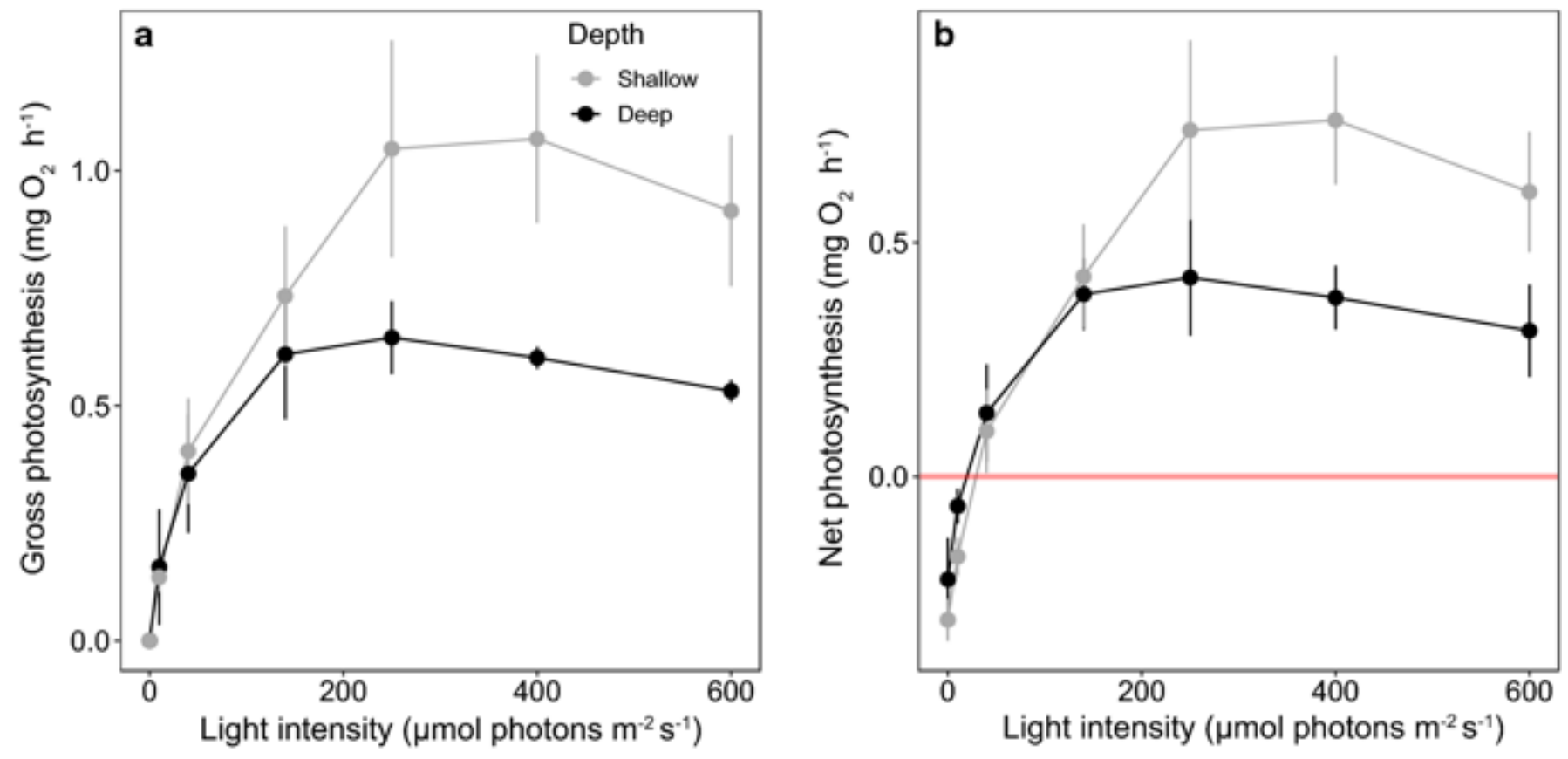
$\mathrm{O}_{2}$ evolution as a function of light intensity in Euphyllia paradivisa measured using respiration metabolic chambers. Mean (dots) and SE (error bars) values of the $\mathbf{a}$ gross and $\mathbf{b}$ net photosynthesis $\left(\mathrm{mg} \mathrm{O}_{2} \mathrm{~h}^{-1}\right.$ ) of shallow ( $5 \mathrm{~m}$; represented in gray, $\left.n=6\right)$ and deep ( $50 \mathrm{~m}$; represented in black, $n=3$ ) fragments of $E$. paradivisa, following 20 min incubation under increasing light intensities $\left(0,10,40,140,250,400\right.$, and $600 \mu \mathrm{mol}$ photons $\left.\mathrm{m}^{-2} \mathrm{~s}^{-1}\right)$. The red line represents the values in which respiration and $\mathrm{O}_{2}$ synthesis are equal

Table 1 Photosynthetic parameters obtained from the photosynthesis versus irradiance (P-E) curves measured by respiration metabolic chambers

\begin{tabular}{|l|l|l|l|l|l|}
\hline & Normalized to & $\alpha$ & $\boldsymbol{E}_{\mathrm{c}}$ & $\boldsymbol{P}_{\max }$ & $\boldsymbol{E}_{\mathrm{k}}$ \\
\hline Shallow & Polyp volume & $0.009 \pm 0.002$ & $40 \pm 7.3$ & $1.007 \pm 0.2$ & $122 \pm 20$ \\
\hline Deep & Polyp volume & $0.178 \pm 0.009$ & $29 \pm 13.4$ & $0.87 \pm 0.2$ & $100 \pm 30$ \\
\hline Shallow & $\begin{array}{l}\text { Living tissue } \\
\text { volume }\end{array}$ & $5.8 \mathrm{e}-5 \pm 1.4 \mathrm{e}-5$ & $42 \pm 8.3$ & $0.007 \pm 0.001$ & $130 \pm 23$ \\
\hline Deep & $\begin{array}{l}\text { Living tissue } \\
\text { volume }\end{array}$ & $1.3 \mathrm{e}-4 \pm 8.1 \mathrm{e}-5$ & $29 \pm 13.4$ & $0.006 \pm 0.002$ & $100 \pm 31$ \\
\hline
\end{tabular}

The slope $(\alpha)$ represents the photosynthetic efficiency, $E_{\mathrm{c}}$ is the irradiance compensation point and $E_{\mathrm{k}}$ is the saturation irradiance of Euphyllia paradivisa. Data represent the mean $\pm \mathrm{SE}$ of each parameter

\section{Symbiodiniaceae genetic identification}

In all our samples, we found Symbiodiniaceae from the genus Cladocopium (formerly known as clade $\mathrm{C}$ ). Although we cannot eliminate the possibility that the corals had changed their algal symbionts during the 3-year period of the experiment, we can conclude that the different photosynthetic performances of the shallow and deep fragments presented in this study are not a results of different algal symbionts genus at the time of analyses.

\section{Discussion}

In light of the severe deterioration of shallow reefs, it was suggested that MCEs may serve as a source of replenishment for their affected shallow counterparts. In order to assess this suggested scenario, we successfully transplanted the mesophotic coral, Euphyllia paradivisa, from $50 \mathrm{~m}$ to $5 \mathrm{~m}$. This study sought to provide an analysis of the photosynthetic characteristics of a mesophotic coral and evaluate its photoacclimation potential following long-term transplantation to the shallow environment. Moreover, this study provides a comparison between transplanted (shallow) and native (deep) fragments from the same colony, and therefore of the same genotype after 3 years. 
Since the distribution of E. paradivisa is strictly mesophotic in the GoE/A (Eyal et al. 2016; Tamir et al. 2019), we were surprised to find higher survival rates among the fragments that were transplanted from depth to the shallow site compared to the deep fragments that were left as a control group in their natural habitat at $50 \mathrm{~m}$. The corals transplanted to the shallow site were placed on an elevated platform, as describes in previous deep-to-shallow coral transplantations (Cohen and Dubinsky 2015), while the deep fragments were left in their natural position. This difference between shallow and deep fragments may explain the higher survival of shallow fragments following the transplantation, despite the higher light conditions. As MCEs are mainly characterized by a light gradient (Lesser et al. 2009; Eyal et al. 2016), and reef corals are considered mostly autotrophic due to their symbiotic relationship with zooxanthellae (Muscatine et al. 1981), corals must balance the reduced light availability to maintain their energetic requirements. In our genetic analysis of the algal symbiont, we found that all our corals harbored the same Symbiodiniaceae genus, Cladocopium. Therefore, we consider all of the differences in photosynthetic performances to result from photoacclimation of the photosynthetic apparatus rather than from a genetic shift in the algal community. The transplanted fragments (i.e., shallow fragments) of E. paradivisa presented evidence of photoacclimation to a high light regime, while their native, mesophotic, counterparts were more efficient at utilizing low light (Figs. 2, 3, 4, 5). Previous studies have investigated the changes in zooxanthellae densities and chlorophyll a concentration along a depth gradient or following transplantation (reviewed by Kahng et al. 2014). Most reports indicated a decrease in the symbiotic algae density along with an increase in chlorophyll a concentration per cell in deeper corals or low-light conditions (Titlyanov et al. 2001; Mass et al. 2007), while others showed that both parameters will increase with depth (Falkowski and Dubinsky 1981; Cohen and Dubinsky 2015; Polinski and Voss 2018). Results of the current study revealed both higher zooxanthellae densities and higher chlorophyll a concentration in the deep corals that remained in their native habitat (Fig. 1). The higher zooxanthellae density and chlorophyll a concentration may assist mesophotic corals to capture more light and produce more photosynthates (Cohen and Dubinsky 2015). The lower values of those parameters in shallow fragments may result from ultraviolet radiation, high PAR, and the formation of reactive oxygen species that are all known to negatively affect zooxanthellae (Gleason and Wellington 1995; Lesser 1996). An additional factor that may have affected the zooxanthellae and chlorophyll a is a difference in temperature. Since our study sites differ at most in $1^{\circ} \mathrm{C}$, we find this factor as less probable to cause such significant variation between the deep and shallow fragments. Natively deeper corals were previously shown to present higher quantum yield compared to shallower corals (Lesser et al. 2010). The deep fragments in the current study demonstrated a better photosynthetic efficiency presenting higher PSII quantum yield $\left(F_{v} / F_{m}\right.$ or $\left.\Delta F / F_{m}{ }^{\prime}\right)$ at lower light intensities, as measured with the Diving-PAM (Fig. 2), FIRe (Fig. 3a), and Imaging-PAM (Fig. 4a). The photosynthetic efficiency ( $\alpha$; Table 1 ) and net photosynthesis (Fig. $5 \mathrm{~b}$ ) calculated from the respiration metabolic chambers were also greater in the deep fragments. The shallow fragments, in contrast, presented higher $\sigma_{\text {PSII }}$ (Fig. 3b), $\tau_{\text {Qa }}$ (Fig. 3c), and NPQ (Fig. 3d) values. Those three parameters, which were higher under higher light intensities in the shallow fragments, may indicate a greater dynamic range for light utilization or point to a faster rate of relaxation of the occupied reaction centers of PSII. The higher $\sigma_{\text {PSII }}$ value in shallow fragments may seem counterintuitive when accompanied by lower zooxanthellae density and lower 
chlorophyll a concentration, but as we did not analyze all photosynthetic pigments, we can suggest that there are other accessory pigments that may be found at higher concentration in the shallow fragments. Both shallow and deep fragments presented $E_{k}$ values previously reported for corals found under overhangs, therefore, corals that are experiencing intermediate light intensities (Anthony and Hoegh-Guldberg 2003). Yet, the shallow fragments reached the compensation point $\left(E_{c}\right)$ at higher light intensities (Table 1), indicating that their rate of photosynthesis is lower than their respiration requirements under lower light conditions compared to the deep fragments (Fig. 5b). Furthermore, the transplanted fragments photosynthetic system remained efficient under higher light conditions. Still, the relative electron transfer rate (rETR) was lower in the transplanted shallow corals under low light, and equal to that of the deep corals at 300-400 $\mu$ mol photons $\mathrm{m}^{-2} \mathrm{~s}^{-1}$ (Fig. 4b). However, under high light conditions, the shallow corals revealed a slightly higher rETR (Fig. 4b), which may suggest higher resistance to photoinhibition, i.e., that they gained some advantage over the mesophotic corals in performing photosynthesis under high light conditions and thereby avoided damage to their photosynthetic apparatus. rETR calculation is based on the assumption that photons are evenly distributed between the two photosystems, and on an estimation that $84 \%$ of incident light is absorbed. Although these assumptions may not necessarily hold true, and hence the absolute value of ETR is uncertain, the changes in rETR with environmental parameters are informative nonetheless.

Excluding the parameters derived from the respiration metabolic chambers (Table 1), our measurements demonstrated higher heterogeneity within shallow fragments compared to deep fragments. Similarly, in Edwards and Kim (2010), higher diurnal variability in several photosynthetic parameters was found in shallower parts of the kelp Macrocystis pyrifera compared to deeper samples. "Flickering light effect," caused by surface waves, is more prominent at the upper water column and causes dramatic fluctuations in light intensity (Schubert et al. 2001; Iluz et al. 2012). Hence, shallow environments will experience a less stable light intensity compared to mesophotic environments, which in turn can cause the shallow fragments to display a higher variability in their photosynthetic parameters.

It should be noted that PAM fluorometry is an indirect method for measuring photosynthetic efficiency derived from the fluorescence properties of chlorophyll (Schreiber et al. 1993) and has limitations, especially in corals depending on tissue composition, the presence of the skeleton, and the algal densities (Wangpraseurt et al. 2019). Also, changes in the optical properties resulting from changes in algal symbiont density or photosynthetic pigments concentration may also affect the measurement of photosynthetic rates (Scheufen et al. 2017). Hence, in this study we used different methods for photosynthesis assessment which complement one another and strengthen the results such as the respiration metabolic chambers that supply more direct information regarding photosynthetic efficiency and are influenced by the gas exchange of the deeper layers of coral tissue. Moreover, in all our experimental simulations, while we increased or decreased the light intensities, we did not modify the spectrum of the actinic light. Mass et al. (2007) has noted the issue of using non-ambient light-spectra for mesophotic coral measurements, and we should take into consideration that deeper corals might be more adjusted to a "bluer" light (Kinzie et al. 1984; Kinzie and Hunter 1987), whether through the possession of blue absorbing pigments (Smith et al. 2017) fluorescent proteins (Eyal et al. 2015), 
different composition of the photosynthetic apparatus (i.e., different pigmentation ratios; Kaiser et al. 1993, Einbinder et al. 2016), or other unknown pathways. Moreover, coral photophysiology may be actually impaired by other, longer, wavelengths as demonstrated by Wijgerde et al. (2014).

Research in the field of mesophotic coral physiology and photobiology is crucial, now more than ever, as the interest in mesophotic coral ecosystems increases, while shallow coral reefs are undergoing mass mortality events (Hoegh-Guldberg et al. 2007; Ainsworth et al. 2016; Hughes et al. 2018). Our results only partially answer the question regarding the potential of mesophotic corals to successfully inhabit shallower reefs. However, we provide a novel example of the changes in photosynthetic performances after a successful long-term transplantation of a mesophotic coral to the shallow environment. Unlike previous mesophotic-to-shallow transplantation attempts (Einbinder et al. 2016; Laverick and Rogers 2018), the majority of our $E$. paradivisa transplanted fragments survived after 3 years despite the significant change in the light conditions upon transplantation as described by Eyal et al. (2016). Additionally, as the photophysiological response of the corals in this study did not follow the accepted paradigms regarding photoacclimation, it is possible that they have other photoacclimation mechanisms that are yet to be discovered.

\section{References}

1. Ainsworth TD, Heron SF, Ortiz JC, Mumby PJ, Grech A, Ogawa D, Eakin CM, Leggat W (2016) Climate change disables coral bleaching protection on the Great Barrier Reef. Science 352:338-342

2. Alamaru A, Loya Y, Brokovich E, Yam R, Shemesh A (2009) Carbon and nitrogen utilization in two species of Red Sea corals along a depth gradient: insights from stable isotope analysis of total organic material and lipids. Geochimica et Cosmochimica Acta 73:5333-5342

3. Anthony KRN, Hoegh-Guldberg O (2003) Variation in coral photosynthesis, respiration and growth characteristics in contrasting light microhabitats: an analogue to plants in forest gaps and understoreys? Funct Ecol 17:246-259

4. Anthony KRN, Hoogenboom MO, Connolly SR (2005) Adaptive variation in coral geometry and the optimization of internal colony light climates. Funct Ecol 19:17-26

5. Bates D, Mächler M, Bolker B, Walker S (2015) Fitting linear mixed-effects models using Ime4. J Stat Softw 67(1):1-48

6. Beer S, Bjork M, Beardall J (2014) Photosynthesis in the marine environment. Wiley, New York

7. Benayahu Y, Loya Y (1985) Settlement and recruitment of a soft coral: why is Xenia macrospiculata a successful colonizer? Bull Mar Sci 36:177-188

8. Bongaerts P, Ridgway T, Sampayo EM, Hoegh-Guldberg O (2010) Assessing the 'deep reef refugia' hypothesis: focus on Caribbean reefs. Coral Reefs 29:309-327 
9. Cantin NE, Cohen AL, Karnauskas KB, Tarrant AM, McCorkle DC (2010) Ocean warming slows coral growth in the central Red Sea. Science 329:322-325

10. Chalker B (1981) Simulating light-saturation curves for photosynthesis and calcification by reef-building corals. Mar Biol 63:135-141

11. Chalker BE, Dunlap WC, Oliver JK (1983) Bathymetric adaptations of reef-building corals at Davies Reef, Great Barrier Reef, Australia. II. Light saturation curves for photosynthesis and respiration. J Exp Mar Bio Ecol 73:37-56

12. Cohen I, Dubinsky Z (2015) Long term photoacclimation responses of the coral Stylophora pistillata to reciprocal deep to shallow transplantation: photosynthesis and calcification. Front Mar Sci 2:45

13. Cohen I, Dubinsky Z, Erez J (2016) Light enhanced calcification in hermatypic corals: New insights from light spectral responses. Fronts Mar Sci 2:122

14. Edwards MS, Kim KY (2010) Diurnal variation in relative photosynthetic performance in giant kelp Macrocystis pyrifera (Phaeophyceae, Laminariales) at different depths as estimated using PAM fluorometry. Aquat Bot 92:119-128

15. Einbinder S, Gruber DF, Salomon E, Liran O, Keren N, Tchernov D (2016) Novel adaptive photosynthetic characteristics of mesophotic symbiotic microalgae within the reefbuilding coral, Stylophora pistillata. Front Mar Sci 3:195

16. Enríquez S, Méndez ER, Hoegh-Guldberg O, Iglesias-Prieto R (2017) Key functional role of the optical properties of coral skeletons in coral ecology and evolution. Proc R Soc Lond B Biol Sci 284(1853):20161667

17. Eyal-Shaham L, Eyal G, Tamir R, Loya Y (2016) Reproduction, abundance and survivorship of two Alveopora spp. in the mesophotic reefs of Eilat, Red Sea. Sci Rep 6:20964

18. Eyal G, Wiedenmann J, Grinblat M, D’Angelo C, Kramarsky-Winter E, Treibitz T, Ben-Zvi O, Shaked Y, Smith TB, Harii S, Denis V, Noyes T, Tamir R, Loya Y (2015) Spectral diversity and regulation of coral fluorescence in a mesophotic reef habitat in the Red Sea. PLoS One 10:e0128697

19. Eyal G, Eyal-Shaham L, Cohen I, Tamir R, Ben-Zvi O, Sinniger F, Loya Y (2016) Euphyllia paradivisa, a successful mesophotic coral in the northern Gulf of Eilat/Aqaba, Red Sea. Coral Reefs 35:91-102

20. Eyal G, Cohen I, Eyal-Shaham L, Ben-Zvi O, Tikochinski Y, Loya Y (2019) Photoacclimation and induction of light-enhanced calcification in the mesophotic coral Euphyllia paradivisa. R Soc Open Sci 6:180527

21. Falkowski PG, Dubinsky Z (1981) Light-shade adaptation of Stylophora pistillata, a hermatypic coral from the Gulf of Eilat. Nature 289:172-174 
22. Falkowski PG, Jokiel PL, Kinzie RA (1990) Irradiance and corals. Ecosystems of the world 25:89-107

23. Feldman B, Shlesinger T, Loya Y (2018) Mesophotic coral-reef environments depress the reproduction of the coral Paramontastraea peresi in the Red Sea. Coral Reefs 37:201214

24. Fitt WK, Gates RD, Hoegh-Guldberg O, Bythell JC, Jatkar A, Grottoli AG, Gomez M, Fisher $P$, Lajuenesse TC, Pantos O, Iglesias-Prieto R, Franklin DJ, Rodrigues LJ, Torregiani JM, van Woesik R, Lesser MP (2009) Response of two species of Indo-Pacific corals, Porites cylindrica and Stylophora pistillata, to short-term thermal stress: the host does matter in determining the tolerance of corals to bleaching. J Exp Mar Bio Ecol 373:102-110

25. Gleason D, Wellington $G$ (1995) Variation in UVB sensitivity of planula larvae of the coral Agaricia agaricites along a depth gradient. Mar Biol 123:693-703

26. Groves SH, Holstein DM, Enochs IC, Kolodzeij G, Manzello DP, Brandt ME, Smith TB (2018) Growth rates of Porites astreoides and Orbicella franksi in mesophotic habitats surrounding St. Thomas, US Virgin Islands. Coral Reefs 37:345-354

27. Hinderstein M, Marr JCA, Martinez FA, Dowgiallo MJ, Puglise KA, Pyle RL, Zawada DG (2010) Theme section on "mesophotic coral ecosystems: characterization, ecology, and management". Coral Reefs 29:247-251

28. Hoegh-Guldberg O, Mumby PJ, Hooten AJ, Steneck RS, Greenfield P, Gomez E, Harvell $\mathrm{CD}$, Sale PF, Edwards AJ, Caldeira K, Knowlton N, Eakin CM, Iglesias-Prieto R, Muthiga N, Bradbury RH, Dubi A, Hatziolos E (2007) Coral reefs under rapid climate change and ocean acidification. Science 318:1737-1742

29. Holstein DM, Smith TB, Gyory J, Paris CB (2015) Fertile fathoms: Deep reproductive refugia for threatened shallow corals. Sci Rep 5:12407

30. Hughes TP, Anderson KD, Connolly SR, Heron SF, Kerry JT, Lough JM, Baird AH, Baum JK, Berumen ML, Bridge TC, Claar DC, Eakin CM, Gilmour JP, Graham NAJ, Harrison H, Hobbs JPA, Hoey AS, Hoogenboom M, Lowe RJ, McCulloch MT, Pandolfi JM, Prachett M, Schoepf V, Torda G, Wilson SK (2018) Spatial and temporal patterns of mass bleaching of corals in the Anthropocene. Science 359:80-83

31. Iluz D, Alexandrovich I, Dubinsky Z (2012) The enhancement of photosynthesis by fluctuating light. In: Artificial photosynthesis. BoD-Books on demand, pp 115-134

32. Jeffrey SW, Humphrey GF (1975) New spectrophotometric equations for determining chlorophylls a1, b1, c1 and c2 in higher plants, algae and natural phytoplankton. Biochem Physiol Pflanz 167:191-194

33. Jokiel PL (1978a) Effects of water motion on reef corals. J Exp Mar Bio Ecol 35:87-97

34. Jokiel PL (1978b) Coral growth: buoyant weight technique. In: Stoddart DR, Johannes RE (eds) Coral reefs: research methods. UNESCO, Paris 
35. Kahng SE, Garcia-Sais JR, Spalding HL, Brokovich E, Wagner D, Weil E, Hinderstein L, Toonen RJ (2010) Community ecology of mesophotic coral reef ecosystems. Coral Reefs 29:255-275

36. Kahng SE, Copus JM, Wagner D (2014) Recent advances in the ecology of mesophotic coral ecosystems (MCEs). Curr Opin Environ Sustain 7:72-81

37. Kahng SE, Akkaynak D, Shlesinger T, Hochberg EJ, Wiedenmann J, Tamir R, Tchernov D (2019) Light, temperature, photosynthesis, heterotrophy, and the lower depth limits of mesophotic coral ecosystems. Mesophotic coral ecosystems. Springer, Berlin, pp 801828

38. Kaiser P, Schlichter D, Fricke HW (1993) Influence of light on algal symbionts of the deep water coral Leptoseris fragilis. Mar Biol 117:45-52

39. Kinzie RA, Jokiel PL, York R (1984) Effects of light of altered spectral composition on coral zooxanthellae associations and on zooxanthellae in vitro. Mar Biol 78:239-248

40. Kinzie RA, Hunter T (1987) Effect of light quality on photosynthesis of the reef coral Montipora verrucosa. Mar Biol 94:95-109

41. Kramer N, Eyal G, Tamir R, Loya Y (2019) Upper mesophotic depths in the coral reefs of Eilat, Red Sea, offer suitable refuge grounds for coral settlement. Sci Rep 9:2263

42. Kuznetsova A, Brockhoff PB, Christensen RHB (2017) ImerTest package: tests in linear mixed effects models. J Stat Softw 82:1-26

43. LaJeunesse TC, Parkinson JE, Gabrielson PW, Jeong HJ, Reimer JD, Voolstra CR, Santos SR (2018) Systematic revision of symbiodiniaceae highlights the antiquity and diversity of coral endosymbionts. Curr Biol 28:2570-2580

44. Laverick JH, Rogers AD (2018) Experimental evidence for reduced mortality of Agaricia lamarcki on a mesophotic reef. Mar Environ Res 134:37-43

45. Lenth R (2018) emmeans: Estimated marginal means, aka least-squares means, $R$ package Version 1.4.3. https://CRAN.R-project.org/package=emmeans

46. Lesser MP (1996) Elevated temperatures and ultraviolet radiation cause oxidative stress and inhibit photosynthesis in symbiotic dinoflagellates. Limnol Oceanogr 41:271-283

47. Lesser PM (2000) Depth-dependent photoacclimatization to solar ultraviolet radiation in the Caribbean coral Montastraea faveolata. Mar Ecol Prog Ser 192:137-151

48. Lesser MP, Slattery M, Leichter JJ (2009) Ecology of mesophotic coral reefs. J Exp Mar Bio Ecol 375:1-8

49. Lesser MP, Slattery M, Stat M, Ojimi M, Gates RD, Grottoli A (2010) Photoacclimatization by the coral Montastraea cavernosa in the mesophotic zone: light, food, and genetics.

Ecology 91:990-1003 
50. Loya Y, Eyal G, Treibitz T, Lesser MP, Appeldoorn R (2016) Theme section on mesophotic coral ecosystems: advances in knowledge and future perspectives. Coral Reefs 35:1-9

51. Maida M, Coll JC, Sammarco PW (1994) Shedding new light on scleractinian coral recruitment. J Exp Mar Bio Ecol 180:189-202

52. Mass T, Einbinder S, Brokovich E, Shashar N, Vago R, Erez J, Dubinsky Z (2007) Photoacclimation of Stylophora pistillata to light extremes: metabolism and calcification. Mar Ecol Prog Ser 334:93-102

53. Mundy CN, Babcock RC (1998) Role of light intensity and spectral quality in coral settlement: implications for depth-dependent settlement? J Exp Mar Bio Ecol 223:235255

54. Muscatine $L(1990)$ The role of symbiotic algae in carbon and energy flux in reef corals. In: Dubinsky Z (ed) Ecosystems of the world: coral reefs. Elsevier, New York, pp 75-78

55. Muscatine L, Porter JW (1977) Reef corals: mutualistic symbioses adapted to nutrientpoor environments. BioScience 27:454-460

56. Muscatine L, McCloskey LR, Marian RE (1981) Estimating the daily contribution of carbon from zooxanthellae to coral animal respiration. Limnol Oceanogr 26:601-611

57. Nir O, Gruber DF, Einbinder S, Kark S, Tchernov D (2011) Changes in scleractinian coral Seriatopora hystrix morphology and its endocellular Symbiodinium characteristics along a bathymetric gradient from shallow to mesophotic reef. Coral Reefs 30:1089

58. Pochon X, Putnam HM, Burki F, Gates RD (2012) Identifying and characterizing alternative molecular markers for the symbiotic and free-living dinoflagellate genus Symbiodinium. PLoS One 7:e29816

59. Polinski JM, Voss JD (2018) Evidence of photoacclimatization at mesophotic depths in the coral-Symbiodinium symbiosis at Flower Garden Banks National Marine Sanctuary and McGrail Bank. Coral Reefs 37:779-789

60. Scheufen T, Iglesias-Prieto R, Enriquez S (2017) Changes in the number of symbionts and Symbiodinium cell pigmentation modulate differentially coral light absorption and photosynthetic performance. Front Mar Sci 4:309

61. Schreiber U, Neubauer C, Schliwa U (1993) PAM fluorometer based on mediumfrequency pulsed Xe-flash measuring light: a highly sensitive new tool in basic and applied photosynthesis research. Photosynth Res 36:65-72

62. Schubert H, Sagert S, Forster RM (2001) Evaluation of the different levels of variability in the underwater light field of a shallow estuary. Helgol Mar Res 55:12-22

63. Shlesinger T, Grinblat M, Rapuano H, Amit T, Loya Y (2018) Can mesophotic reefs replenish shallow reefs? Reduced coral reproductive performance casts a doubt. Ecology 99:421-437 
64. Smith EG, D'Angelo C, Sharon Y, Tchernov D, Wiedenmann J (2017) Acclimatization of symbiotic corals to mesophotic light environments through wavelength transformation by fluorescent protein pigments. Proc R Soc Lond B Biol Sci 284:1858

65. Team RC (2013) R: A language and environment for statistical computing. R Foundation for Statistical Computing, Vienna

66. Tamir R, Eyal G, Kramer N, Laverick JH, Loya Y (2019) Light environment drives the shallow-to-mesophotic coral community transition. Ecosphere 10:e02839

67. Titlyanov EA, Titlyanova TV, Yamazato K, van Woesik R (2001) Photo-acclimation dynamics of the coral Stylophora pistillata to low and extremely low light. J Exp Mar Bio Ecol 263:211-225

68. Trench RK, Harley JL (1971) The physiology and biochemistry of zooxanthellae symbiotic with marine coelenterates. II. liberation of fixed $14 \mathrm{C}$ by zooxanthellae in vitro. Proc $R$ Soc Lond B Biol Sci 177:237-250

69. Veron JEN (1990) New scleractinia from Japan and other Indo-West Pacific countries. Galaxea 9:95-173

70. Veron JEN (1995) Corals in time and space. University New South Wales Press, Sydney

71. Wangpraseurt D, Lichtenberg M, Jacques SL, Larkum AWD, Kühl M (2019) Optical properties of corals distort variable chlorophyll fluorescence measurements. Plant Physiol 179:1608-1619

72. Wijgerde T, van Melis A, Silva CIF, Leal MC, Vogels L, Mutter C, Osinga R (2014) Red light represses the photophysiology of the scleractinian coral Stylophora pistillata. PLoS ONE 9:e92781-e92781

73. Yamashiro H, Nishira M (1995) Phototaxis in Fungiidae corals (Scleractinia). Mar Biol 124:461-465

Acknowledgements

We would like to thank the Interuniversity Institute for Marine Sciences in Eilat (IUI) for logistical support and making their facilities available to us. We thank $\mathrm{M}$. Fine and his lab for assisting us with the Imaging-PAM measurements and I. Cohen for his assistance in analyzing the respiration metabolic chambers results. We are grateful to the Marine Photosynthesis Course in the IUI for their contribution to the final stage of this research. We also thank N. Paz for her proofreading and the anonymous reviewers for their much-appreciated comments.

Funding

Funding was provided by the Israel Science Foundation (Grant No. 1191/16), Ministry of Science and Technology, Israel (Grant No. 3-18487), European Union's Horizon 2020 research and innovation program under a Marie Skłodowska-Curie (Grant No. 796025).

Author information 


\section{Author notes}

1. Or Ben-Zvi and Raz Tamir have contributed equally to this work.

\section{Affiliations}

1. School of Zoology, Faculty of Life Sciences, Tel-Aviv University, Tel Aviv, Israel
- Or Ben-Zvi
- , Raz Tamir
- \& Yossi Loya

2. The Interuniversity Institute for Marine Sciences in Eilat, Eilat, Israel

- Or Ben-Zvi

○ , Raz Tamir

$\circ \quad \&$ Tal Benaltabet

3. The Institute of Life Sciences, The Hebrew University of Jerusalem, Jerusalem, Israel

○ Nir Keren

4. The Leon H. Charney School of Marine Sciences, University of Haifa, Haifa, Israel

- Dan Tchernov

- \& Ilana Berman-Frank

5. Applied Physics Department and The Center for Nanoscience and Nanotechnology, The Hebrew University of Jerusalem, Jerusalem, Israel

○ Yuval Kolodny

6. Institute of Earth Sciences, The Hebrew University of Jerusalem, Jerusalem, Israel

- Tal Benaltabet

7. Department of Soil and Water Sciences, The Robert H. Smith Faculty of Agriculture, Food and Environment, The Hebrew University of Jerusalem, Rehovot, Israel

- Harel Bavli

8. Department of Biotechnology Engineering, Ben-Gurion University of the Negev, BeerSheva, Israel

- Mor Friedman

9. Plant Sciences and Genetics in Agriculture, The Robert H. Smith Faculty of Agriculture, Food and Environment, The Hebrew University of Jerusalem, Rehovot, Israel

○ Noga Glanz-Idan 
10. School of Mechanical Engineering, Tel-Aviv University, Tel Aviv, Israel

- Hadar Traugott

11. ARC Centre of Excellence for Coral Reef Studies, School of Biological Sciences, The University of Queensland, St Lucia, Australia

- Gal Eyal

12. The Mina and Everard Goodman Faculty of Life Sciences, Bar Ilan University, Ramat Gan, Israel

- Gal Eyal

\section{Corresponding authors}

Correspondence to Or Ben-Zvi or Raz Tamir or Gal Eyal. 